\begin{tabular}{|l|r|}
\hline \multicolumn{1}{|c|}{ S sciendo } & \begin{tabular}{c} 
NCF $\begin{array}{l}\text { Nordic } \\
\text { Concrete } \\
\text { Federation }\end{array}$ \\
\hline $\begin{array}{l}\text { (C) Article authors. This is an open access article distributed under } \\
\text { the Creative Commons Attribution-NonCommercial-NoDerivs } \\
\text { license. (http://creaticecommons.org/licenses/by.nc-nd/3.0/). }\end{array}$
\end{tabular} \\
\hline & $\begin{array}{r}\text { ISSN online 2545-2819 } \\
\text { ISSN print } \quad \text { 0800-6377 }\end{array}$ \\
\hline DOI: $10.2478 /$ ncr-2021-0004 & $\begin{array}{r}\text { Received: March 26, 2021 } \\
\text { Revision received: June 23, 2021 } \\
\text { Accepted: June 26, 2021 }\end{array}$ \\
\hline
\end{tabular}

\title{
Determination of the Stress Increase of the Unbonded Tendon in a Continuous Concrete Beam at Ultimate Capacity Using Nonlinear Analysis
}

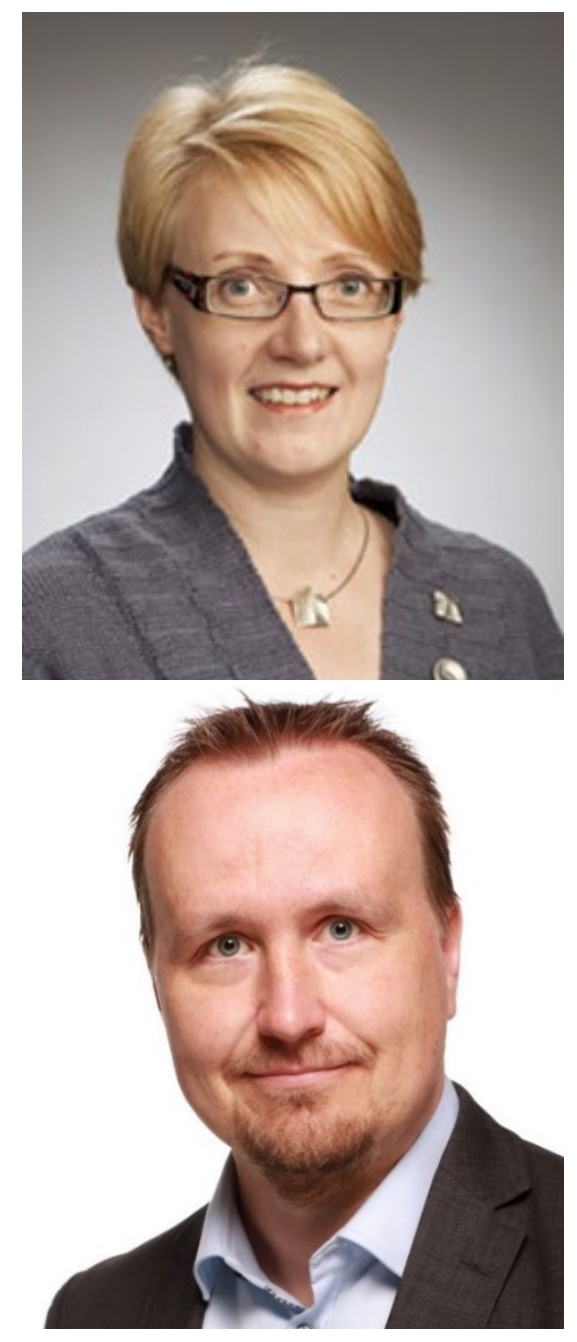

Tarja Nakari, M.Sc

Ph.D. student

Tampere University

Unit of Structural Engineering

Research Group of Concrete and Bridge Structures

PO Box 600

FI-33014 Tampere University

tarja.nakari@tuni.fi

Prof. Dr. Anssi Laaksonen

Tampere University

Unit of Structural Engineering

Research Group of Concrete and Bridge Structures

PO Box 600

FI-33014 Tampere University

anssi.laaksonen@tuni.fi

\section{ABSTRACT}

Predicting the stress increase of an unbonded tendon in a post-tensioned continuous concrete beam at ultimate capacity is more difficult than when bonded tendons are used. The failure mechanisms of the continuous beam are also different to that of the simple-span beam. The loading type, 
ductility of the support area and moment redistribution influence the behaviour of the continuous structures. In this research, the simplified nonlinear analysis was used for predicting the unbonded tendon stress increase at ultimate capacity in continuous two-span beams. The model is based on the moment-curvature relationships of the reinforced concrete cross-sections under different compressive forces and deformations of the continuous beam under loading. The results have been compared with the experimental results of recent studies found in the literature. In addition, 92 unbonded post-tensioned two-span beams with different reinforcements have been examined by using the model and compared to the results obtained from empirical equations from the literature. The results from the nonlinear analysis correspond well to the results from the other models up to the reinforcement ratio of 0.35 . The calculated values of the maximum moment capacity at the centre support were close to the results from the test beams.

Key words: Unbonded tendons, mono-strands, post-tensioned beams, stress increase.

1.

INTRODUCTION

Internal unbonded tendons in post-tensioned structures are, nowadays, commonly used in cast insitu concrete building structures, such as multi-storey car park buildings and yard decks. Recently, the use of this technology has also expanded to other types of buildings, for example, commercial buildings. In unbonded post-tensioned concrete structures, the unbonded mono-strands are greased and covered by plastic sheathing to avoid corrosion and provide minimum friction between mono-strands and concrete. Such structures form an efficient and economical loadcarrying system which allows the reduction of cross-section dimensions, for instance, the slab thickness. The post-tensioning of the concrete structure also reduces cracks and deflection of the structures. Unbonded mono-strands are lightweight, low-cost and easy to install, and no grouting is needed. The design of the post-tensioned structure is often based on permitted stresses at service loads. The structures must also meet the requirements of the ultimate state.

The methods of reasonably predicting the stress increase in post-tensioned unbonded tendons at the ultimate limit state have provided a design challenge for structural engineers and researchers over several decades. Many researchers have proposed numerous models and design equations for evaluating the strand stress increment $\Delta \sigma_{\mathrm{p}, \text { ULS }}$ at the ultimate limit state and the nominal flexural capacity of unbonded post-tensioned members [2,4,7-10,12,14,22-23]. Some of these empirical equations have been included in the design codes and specifications, which are continuously updated to match research results. Most of the proposed methods are empirical and based on test data, usually from tests with simple-span beams. Recently, more studies have been conducted to investigate the behaviour of the unbonded post-tensioned continuous members. Theoretical analysis, finite element modelling and laboratory testing of such beams, conducted in Europe, North and South America and Asia, have revealed that the equations which rely on simple beam test data may yield nonconservative results when used in continuous members [1]. New knowledge on the behaviour of unbonded continuous post-tensioned members has shown that the failure mechanisms of the simple-span system and the continuous system are essentially different. For example, ductility of the support area, loading type and moment redistribution influence the behaviour of the continuous structures. 


\section{RESEARCH OBJECTIVE}

The main objective of this research was to determine the maximum moment capacity of the continuous concrete beam post-tensioned with unbonded tendons and the stress increment of the mono-strands at the ultimate limit state by using simplified nonlinear analysis. Experimental results and models found in the literature were introduced as background work studies. The model utilises the finite element method, the moment-curvature relationships of the reinforced concrete cross-sections and deformations of the continuous structure under loading. The model is compared with the experimental test results of various studies found in the literature, as well as the results obtained by using the formulas of design standards and the models presented by a few researchers. In addition, a parametric study was carried out to investigate the effect of different amounts of non-prestressed reinforcement in the tension and compression fibres on the stress increase of the unbonded tendon at the ultimate limit state in continuous two-span beams.

This study is part of a larger research project aimed at examining the function of the support area of the post-tensioned continuous concrete structures, the formation of the plastic hinges, the moment redistribution and the ductility of structures. In this first step, the reliability of the model is clarified. Later, test beams will be manufactured and tested at the laboratory of Tampere University.

\section{3.}

\section{LITERATURE REVIEW}

In 1971, the empirical expression for the stress increment of the unbonded tendon at ultimate capacity was proposed by Mattock et al. [2]. The expression is based on experimental tests of seven simply supported beams, three continuous two-span T-beams and other previous experimental results, and it was adapted to the ACI code. The primary variables in their tests were the presence and absence of the bond between the tendon and the adjacent concrete and the amount of bonded non-prestressed reinforcement, ordinary rebars or seven wire strands. The behaviour of the test beams demonstrated that the provision of the additional bonded non-prestressed reinforcement will ensure that an unbonded post-tensioned beam will behave as a flexural member and not like a tied-arch model [2].

Cooke et al. conducted tests of nine unbonded and three bonded simply supported one-way prestressed concrete slabs without additional non-prestressed reinforcement in 1981 [3]. The experimental test showed that the unbonded prestressed concrete slabs, where the ratio of the effective prestressing force to the compressive capacity of the cross section is very low (less than 0.11), developed one or two cracks and a small concrete compression zone. Bonded nonprestressed reinforcement in the slab will prevent the formation of a single crack and, thus, increases ductility on the member. Based on their findings, Cooke et al. proposed that the stress increase in an unbonded tendon should not be more than $100 \mathrm{MPa}$ at ultimate flexural capacity [3]. Du and Tao also studied the effects of varying amounts of non-prestressed reinforcement on the ultimate stress in unbonded tendons and on the ultimate strength of the beams. They tested a total of 26 unbonded and bonded prestressed simple-span concrete beams. The results indicated that the stress in unbonded tendons at ultimate capacity can be substantially enhanced by adding an adequate amount of non-prestressed reinforcement for distributing cracks [4].

In 1978, Burns, Charney and Vines conducted tests of two half-scale slabs post-tensioned with unbonded tendons and containing different amounts of bonded reinforcement. Both continuous 
one-way slabs had three equal spans with a span/depth ratio of 44 [5]. The other parameters examined were the loading pattern and the degree of prestressing. The observations were that the relationship between tendon stress increase and deflection was almost linear and only a minor amount of bonded reinforcement ( 0.12 per cent of gross area) in test slab A produced a satisfactory distribution of cracking. In both test slabs, the positive moment hinge formed at or near the end of the tension reinforcement bar in the exterior spans. A slightly premature failure was observed as the result of insufficient anchoring lengths of bonded non-prestressed reinforcement bars [5].

Harajli et al. developed an analytical model to explain the mechanism of the member span-depth ratio $\left(L / d_{\mathrm{p}}\right)$ and its effect on stress increase in unbonded prestressing steel at ultimate capacity [6]. Recently, Harajli has introduced a design expression for unbonded tendon stress $\sigma_{\mathrm{p}, \text { ULS }}$ at ultimate capacity in continuous post-tensioned flexural members based on the plastic analysis and the concept of a collapse mechanism. The expression takes several important parameters into account, such as the continuity of the member, the type of load application, the number of plastic hinges developed in the process of forming a collapse mechanism, the span-depth ratio and the area of bonded non-prestressed reinforcement $[7,8,9]$.

Naaman and Alkhairi (1991) included a bond reduction coefficient $\Omega_{\mathrm{u}}$ in their design equation for computing the stress in unbonded tendons at ultimate capacity [10]. The idea of their method was to convert unbonded post-tensioned beams to the equivalent cases with bonded tendons. The coefficient was influenced by parameters, such as the loading type and span-to-depth ratio of the beam.

Weller presented results from tests of eight single-span and four continuous two-span beams prestressed with unbonded tendons in 1988 [11]. Two of those continuous beams had a rectangular cross-section and another two were T-shaped. As essential results of these tests, it was stated that the decisive variables for the stress increase of the tendon were the strength of the concrete compression zone and the related prestressing force. The adequate amount of reinforcing steel distributed the formation of cracks and ensured the ductile load-bearing behaviour, even when the load is concentrated, as it was in the support area [11].

In 1987, Kordina and Hegger presented a model for the determination of the ultimate strength of flexural members post-tensioned with unbonded tendons [12]. It was based on a systematic evaluation of tests and enables the stress increase of unbonded tendons in the ultimate limit state to be calculated in a simple manner. In the model, the deformations of the member have been assumed to concentrate in the hinge zones, while the other parts remain substantially undeformed. The model takes several parameters into account, like the tendon length, the percentage of prestressing steel, the strength of the concrete, the distribution of the load and the shape of the cross-section. [12] The method is presented in more detail in Chapter 5 and has been used in this study for comparative analyses.

In 2010 Zhou and Zheng conducted tests of 16 continuous two-span beams prestressed with internally post-tensioned unbonded tendons loaded under concentrated static load up to failure [13]. Based on the tests, formulas for the equivalent length of the plastic hinge region and the degree of moment redistribution in a critical section over the inner support were proposed. The test results showed that the rotation capacity of plastic hinges contributed to most of the ultimate stress increases in unbonded tendons [14]. The factors, such as reinforcement indexes and spandepth ratios, affected the rotation capacity of plastic hinges and also influenced the ultimate stress of the unbonded tendon. Later, Zhou and Zheng developed a model to predict the stress increase 
in unbonded tendons of continuous post-tensioned concrete beams at service load and at the ultimate state. The method was calibrated with the experimental data of their previous tests [14].

In 2016, Maguire et al. tested four two-span slab specimens post-tensioned with unbonded tendons and compared the results with existing design models [15]. The tendon stress increase predicted from different design equations, compared to the measured values from tested slabs, was found to be conservative. The researcher also discovered that end force increases are greater nearer the loaded span. This indicates that friction and the distribution of external loads affect the stress increases in an unbonded tendon.

Allouche et al. developed a nonlinear numerical model to predict the tendon stress increment in the continuous, unbonded and partially prestressed concrete members having a rectangular crosssection [16]. Their parametric study showed that the number of plastic hinges that can be developed under a given loading pattern and the type of loading (uniform or concentrated) have significant influence on the tendon stress increase at ultimate capacity. The research group also investigated the effect of lateral confinement on the tendon stress increment by assuming three different degrees of confinement of the concrete compression zone in their model. According to the model, the higher the amount of confinement, the greater the increase in the tendon.

The numerical simulation of unbonded structures tends to be more complex than the bonded case. Kim and Lee proposed in 2012 a flexural behaviour model for a continuous unbonded posttensioned member, including the assumption of an idealised curvature distribution in the maximum moment region from their previous studies. Their expression utilises the bending moment distribution and flexural stiffness ratio along the continuous member to reflect the effect of the loading type and moment redistribution [17]. Vu, Castel and François proposed a nonlinear finite element model for calculating the structural behaviour of post-tensioned prestressed beams with unbonded tendons [18]. Both serviceability and ultimate state were included in their analysis model. The analyses were based on a macro finite element (M.F.E) model, which is characterised mainly by its homogeneous average inertia. The analysis takes into account the concrete tension stiffening effect, the propagation of flexural cracks and the lengthening of the unbonded prestressing tendons due to the load applied [18].

\section{DESCRIPTION OF MODEL}

The linear elastic analysis may be used to determine the nominal moment resistance, assuming that the concrete cross-sections are uncracked. The cracking and nonlinear behaviour of the concrete structure has a significant effect on its bending stiffness and, thus, also on the deformations of the member being bent. In a bonded post-tensioned concrete beam or slab, tendons and reinforcing bars are assumed to have a perfect bond with the concrete after prestressing. The flexural strength, stresses and strains can be defined by using the principles of strain compatibility. Then the change in strain in the tendon at the section of maximum moment is equal to the change in strain in the adjacent concrete. In an unbonded post-tensioned member, there is no bond between the tendon and the surrounding concrete and there is a slip between the tendon and the adjacent concrete. The principles of strain compatibility are no longer fulfilled, but the equal elongation of the prestressing steel and surrounding concrete fibre between two anchor points still exists. The deformations of the member have a substantial effect on the elongation and stress increase of the unbonded tendons and therefore also a significant effect on the maximum flexural capacity. 


\section{1}

\section{The moment-curvature relationship}

A refined calculation of the load-bearing behaviour of concrete beams post-tensioned with unbonded tendons requires consideration of non-linear material behaviour of the reinforced concrete and prestressing steel. Using the material properties of concrete and reinforcing steel, and the assumption of the Bernoulli hypothesis where plane sections remain plane after bending, the moment-curvature relationship for a reinforced concrete cross-section under different axial forces can be calculated. In other words, the dependence of the bending stiffness of the crosssection from the axial force is determined. The axial (tendon) force $N_{\mathrm{p}}$ is formed later in the FEanalysis by bar elements.

A representative moment-curvature line with characteristic points and areas is shown in Figure 1. Three different states can be distinguished from the curve, depending on the degree of loading. [19] At the first state, the concrete cross-section remains uncracked on the tension fibre. At the second state, the concrete member is cracked, and the tensile forces must be taken by the reinforcing steel. At the third state, the curvature increases to the maximum value without the internal moment being significantly increased.

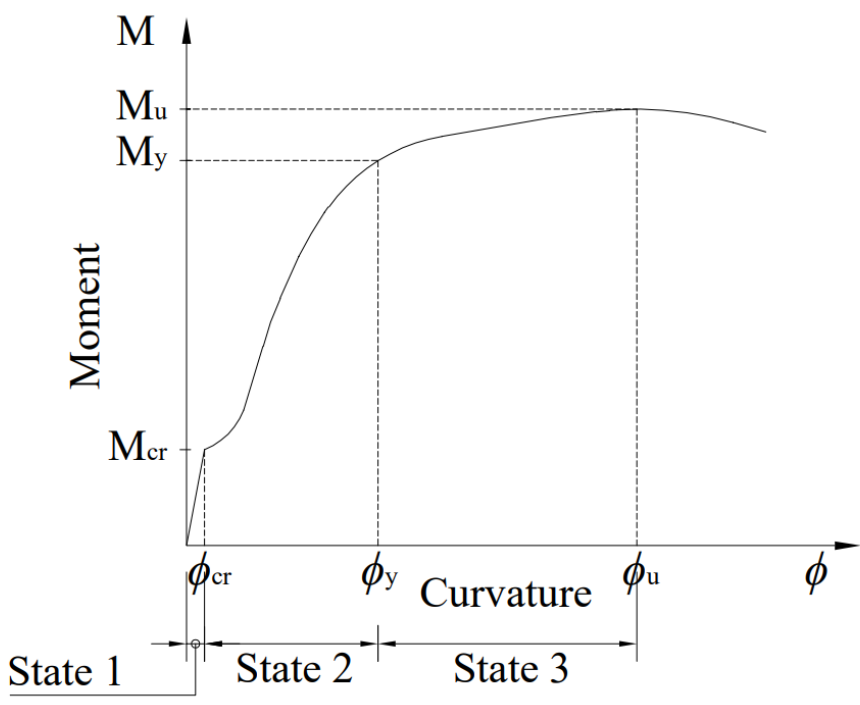

Figure 1 - A representative moment-curvature $M-\phi$-line.

In the determination of the moment-curvature relationship of a reinforced concrete cross-section for the finite element analysis, the compressive force is assumed to act on the centre of gravity of the cross-section. The cross-section is assumed to be totally cracked in the tension fibre because the finite element analysis focuses on the third state of the moment-curvature curve and determines the maximum flexural strength of the unbonded post-tensioned concrete beam at the ultimate limit state. It is well known that tension stiffening has an effect which is different before and after the yielding of reinforcement. But, for the sake of simplicity, the effect of concrete tension stiffening between cracks has been neglected in this model, which could be easier used in practice. The moment-curvature curves with different longitudinal compression force, can be determined from the equilibrium conditions of the internal forces of the cross-section when the strains at the top and bottom fibres are known.

The moment-curvature relationship takes several factors into account that affect ductility of a reinforced concrete structure, e.g. material parameters, position and amount of tension and compression reinforcement and dimensions of the concrete cross-section. In the parametric study, 
the concrete compression strength and the dimensions of the cross-sections have been kept constant, and the variables used were the amount of tension and compression reinforcement and the magnitude of the axial force. The value for the ultimate compression strain is adopted from EN 1992-1-1, and the effect of confinement near the centre support has been ignored in the calculations. The moment-curvature relationships for different cross-sections are calculated without safety factors, so the results from the finite element analysis can be more easily compared with the experimental results from the literature.

The strains, stresses and internal forces of a reinforced T-shaped concrete cross-section used in the parametric study are shown in Figure 2. The selected normal force values have been used to numerically calculate the moment-curvature relations for the cross-section. Those momentcurvature relationships were calculated without any amount of unbonded prestressing steel because the tendon force is taken into account separately. The effective prestress force and its eccentricity have only been added to the FE-model to bar elements. As an example, the momentcurvature relationships of one such cross-section with eight different longitudinal compressive forces have been calculated and are shown in Figure 3.

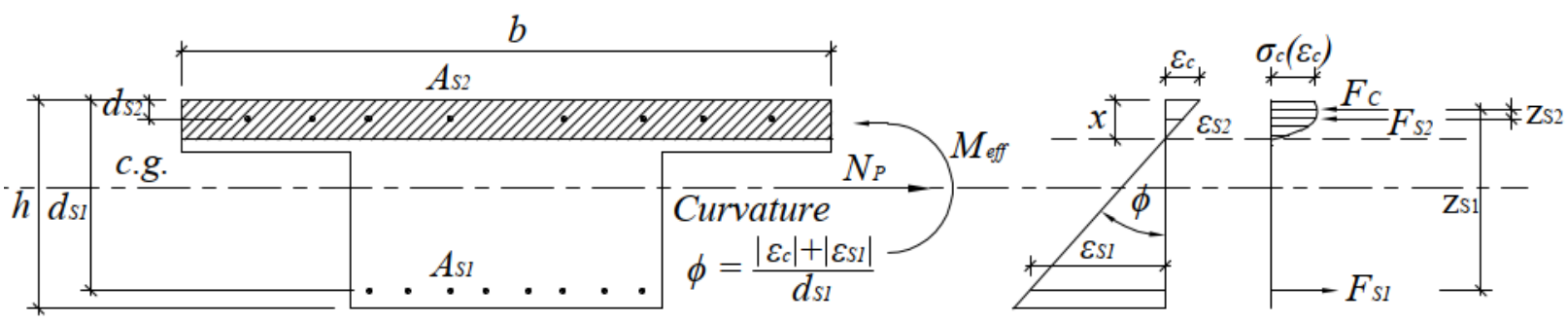

Figure 2 -Strain, stresses and internal forces of the examined reinforced concrete crosssection at state 3.

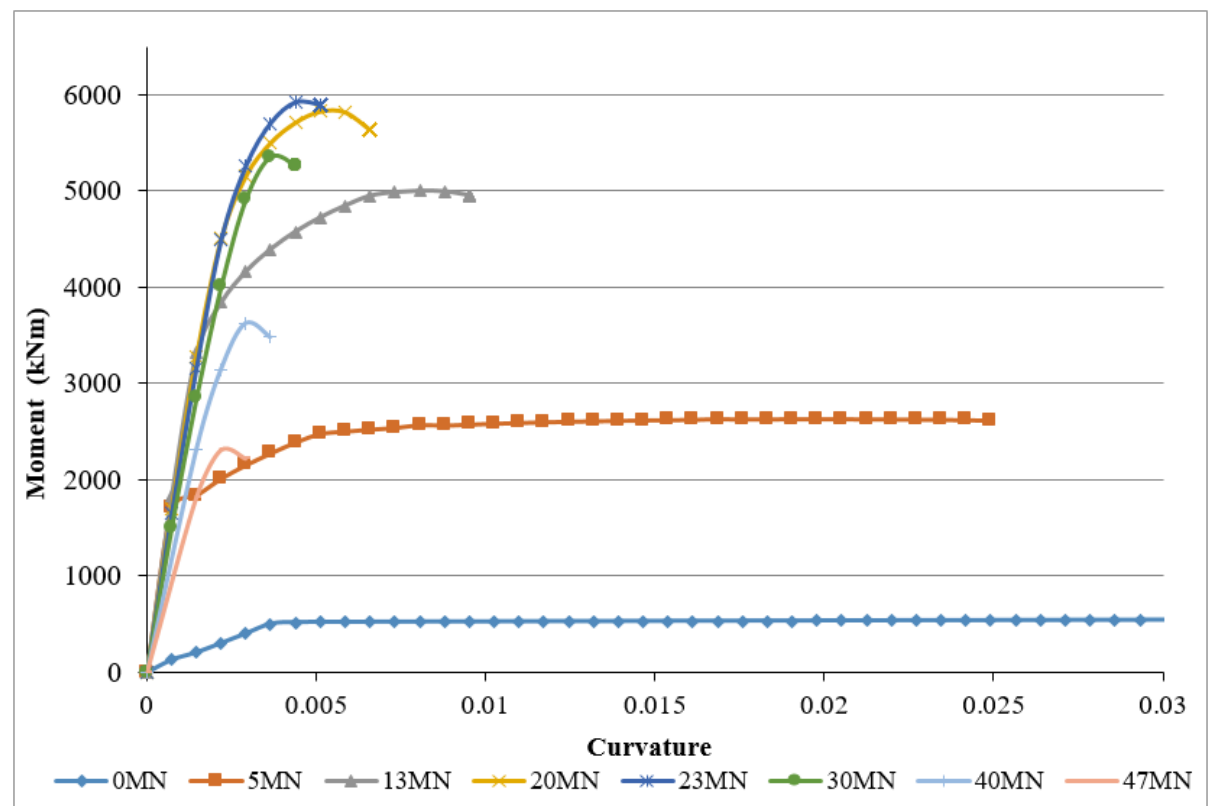

Figure 3 -Moment-curvature lines of a T-shape reinforced cross-section with different longitudinal compression force. 


\section{Concrete}

Among the concrete material models available, the nonlinear stress-strain relation for the concrete under short-term uniaxial loading, according to the European standard EN 1992-1-1 has been chosen to be used in the derivation of the moment-curvature relationships [20]. A very similar relation between $\sigma_{\mathrm{c}}$ and $\varepsilon_{\mathrm{c}}$ for short-term uniaxial compression can be found in Model Code 2010 [21]. The stress-strain relation for the concrete of compression strength $f_{\mathrm{c}}=35 \mathrm{MPa}$ is shown in figure 4. The expression is:

$$
\frac{\sigma_{\mathrm{c}}}{f_{\mathrm{cm}}}=\frac{k \eta-\eta^{2}}{1+(k-2) \eta}
$$

where

$$
\eta=\varepsilon_{\mathrm{c}} / \varepsilon_{c 1}
$$

$\varepsilon_{\mathrm{c} 1}$ is the strain at peak stress, according to EN 1992-1-1 Table 3.1

$k=1,05 E_{\mathrm{cm}} x\left|\varepsilon_{\mathrm{c} 1}\right| / f_{\mathrm{cm}}\left(f_{\mathrm{cm}}\right.$ and $E_{\mathrm{cm}}$ according to Table 3.1$)$

Expression (1) is valid for $0<\left|\varepsilon_{\mathrm{c}}\right|<\left|\varepsilon_{\mathrm{cu}}\right|$ where $\varepsilon_{\mathrm{cu}}$ is the nominal ultimate strain. The value for the ultimate compression strain $\varepsilon_{\mathrm{cu}}$ is $-3.5 \%$ for the concrete of compression strength less than or equal to $50 \mathrm{MPa}$. The strain at peak stress $\varepsilon_{\mathrm{c} 1}$ is $-2,25 \%$ for concrete of compression strength $35 \mathrm{MPa}$.

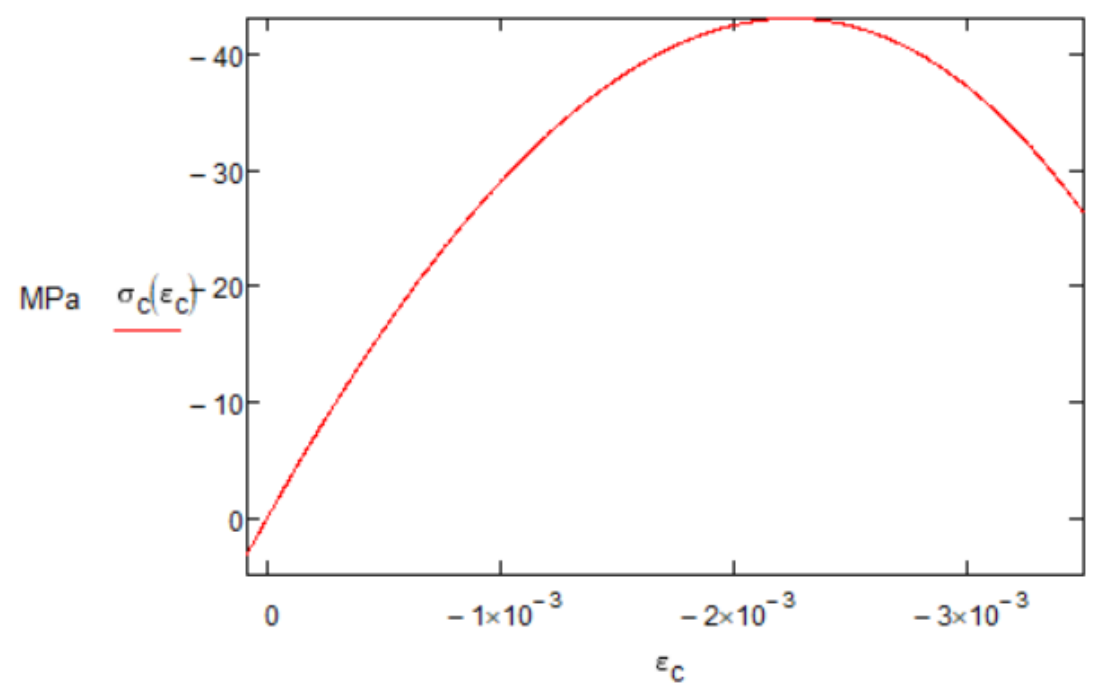

Figure 4 - Stress-strain relationship for the concrete used in the model.

\section{Reinforcing steel}

A bilinear material model without yield strengthening presented in EN 1992-1-1 is adopted for the reinforcing steel under either tension or compression [20]. The strength of the reinforcing steel $f_{\mathrm{yk}}$ used in the derivation of moment-curvature was $500 \mathrm{MPa}$, and the value $\varepsilon_{\mathrm{uk}}$ for the ultimate elongation of the reinforcing steel was $5.0 \%$.

Prestressing steel

The material properties of the prestressing steel used in the nonlinear finite element analysis are according to the European standard EN 1992-1-1 [20]. The characteristic 0.1\% proof-stress of the 
prestressing steel used in the parametric study was $f_{\mathrm{p} 0,1 \mathrm{k}}=1640 \mathrm{MPa}$ and the maximum characteristic tensile strength was $f_{\mathrm{pk}}=1860 \mathrm{MPa}$. Young's modulus of the prestressing steel was $195000 \mathrm{MPa}$. The sum of the stress losses of the tendon, including the friction of the tendon, the shrinkage and creep of the concrete and the relaxation of the prestressing steel, has been assumed to be $15 \%$.

\section{3}

\section{Nonlinear finite element analysis}

The nonlinear finite element analysis program LUSAS [25] was used. In the parametric study, a continuous two-span reinforced concrete beam was modelled by using $3 \mathrm{D}$ beam elements. The length of the beam element was the same as the height of the beam, in this case $800 \mathrm{~mm}$. This was also selected so that deformations at the support area would have a stable output. The examined model formed from three different $\mathrm{T}$-shape cross-sections along the structure can be seen in Figure 5. The effective width of the flanges of each cross-section was determined according to the European standard EN 1992-1-1 [20]. The dimensions of the beam and cross-sections used in the parametric study are shown in Figure 5. The moment-curvature relationships with eight levels of axial force for these reinforced cross-sections were derived and entered as a user-defined material model in the FE-program, seen in Figure 6. The program calculates intermediate values by linear interpolation.

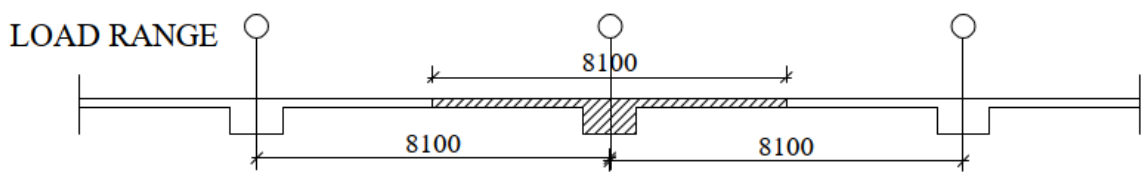

DIMENSION AND LOADS

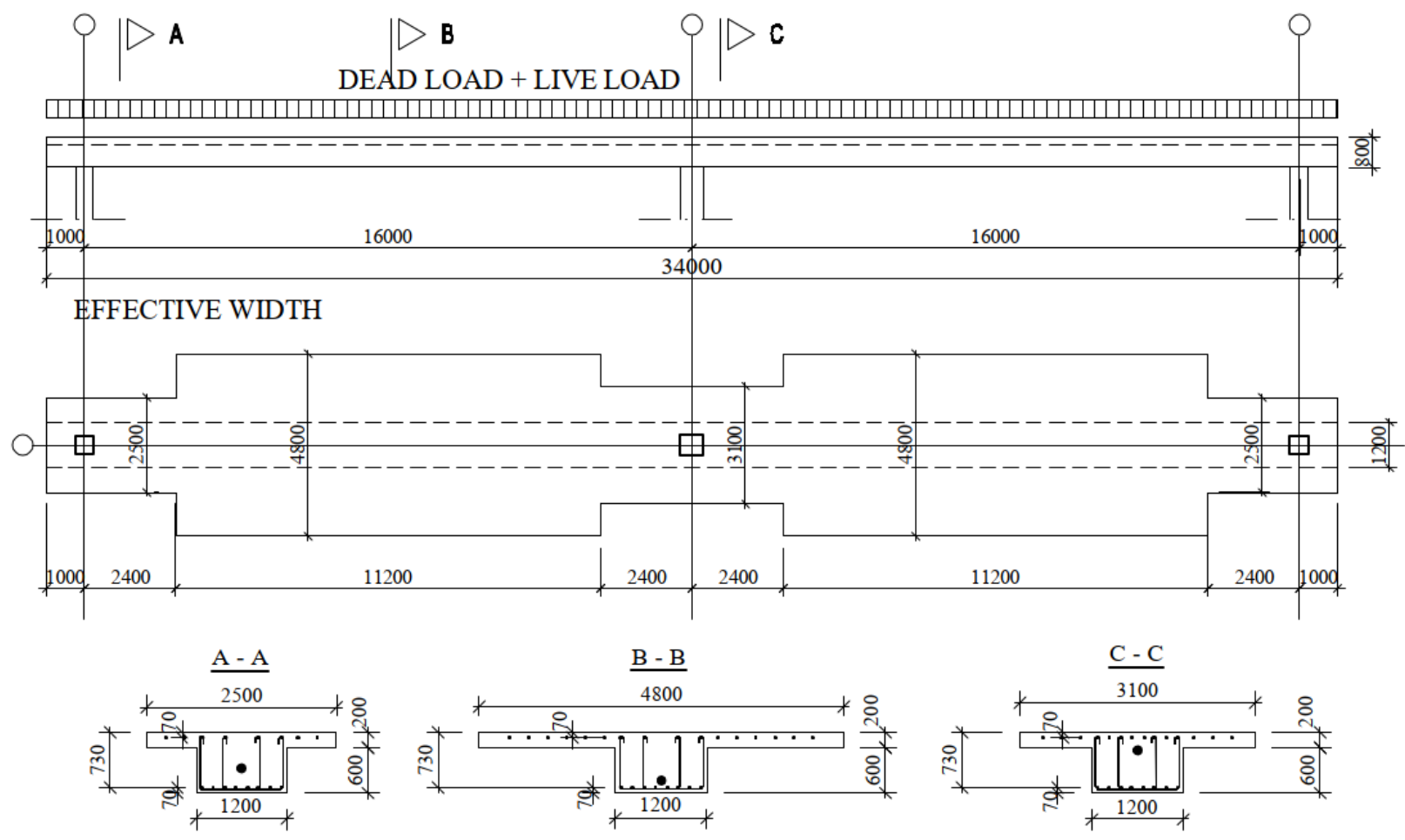

Figure 5 -Dimensions of the beam and cross-sections [mm]. 


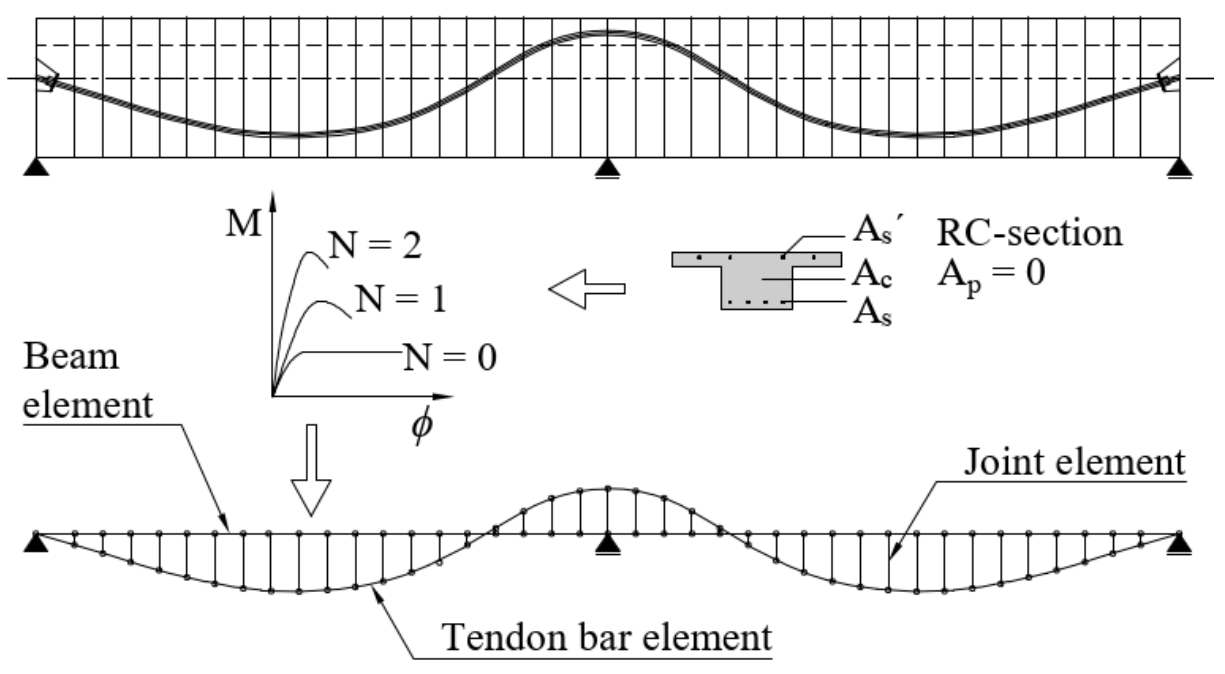

Figure 6-Finite element model of the beam and tendon.

One tendon geometry is used in the parametric study. This geometry is modelled as a resultant of a group of mono-strands, seen in Figures 7. The prestressing force along the beam was defined as the corresponding force in a 3D bar element with the same geometry as a part of the tendon. This is illustrated in Figure 6. The bar elements were modelled separately from the gravity line of the concrete beam conforming to the actual geometry of the tendon resultant. At that point, the tendon force and its eccentricity will be included in the model. This activates both primary and secondary moments to the structure relative to the moment-curvature relations. In the model the prestressing forces are handled as an internal resistance for the beam. The bar element division is such that the nodes are located on the same vertical line as the node in the beam. These nodes are connected by means of 3D-joint-elements. This joint-element connects two nodes by three springs in the local $\mathrm{x}-, \mathrm{y}-$ and $\mathrm{z}$-directions and does not have rotational stiffness. In the direction of the beam axis (xdirection), the elastic stiffness of the spring is set high, but in the other two directions the movement is permitted. The tendon is only rigidly connected to the beams at both ends.

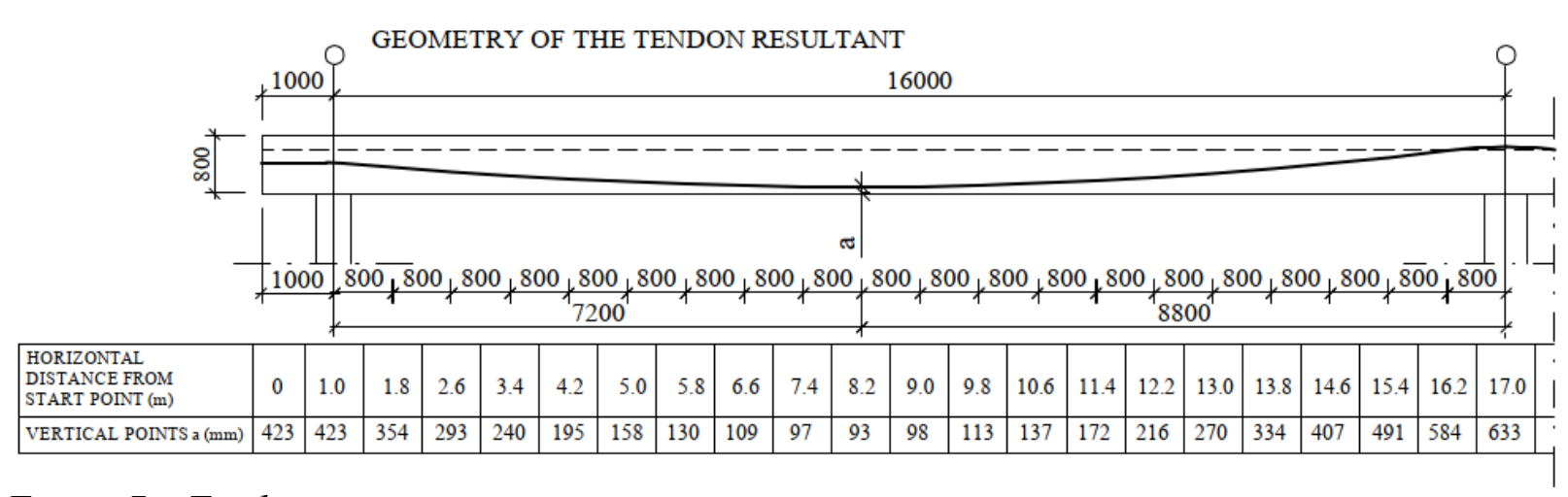

Figure 7 - Tendon geometry.

The additional strain $\Delta \varepsilon_{\mathrm{p}}$ of the tendon that arises based on the curvature of the beam and eccentricity of the tendon from the neutral axis of the beam. However, at the ultimate limit state, the position of the neutral axis varies along the beam. In the area of the maximum moment, the neutral axis moves closer to the compressed edge of the beam. For this reason, the eccentricity of the tendon also changes. In the model the eccentricity of the tendon is constant from the centre of 
gravity line of the beam and does not change with the load. This causes some inaccuracy in the additional strain of the tendon and, thus, consequently in the level of the stress increase.

The studied beam is one beam from the continuous cast in a situ concrete structure shown in Figure 5. The dead load of the beam consists of the weights of the beam itself and the slabs on both sides of the beam. The value of the dead load used in the finite element analysis of the parametric study was $58.5 \mathrm{kN} / \mathrm{m}$. The beam is loaded with a uniform live load from both spans. The load was increased until failure occurred. The bending moment capacity obtained from the model includes the moments from external loads (dead and live loads), as well as the secondary moment. The secondary moment develops when loading the structure in relation to the stiffness of the cross-section.

\section{5.}

\section{VERIFICATION OF THE MODELS WITH TEST BEAMS FROM LITERATURE}

\section{1}

\section{Analysis with simplified model}

Several simplified manual calculation procedures for determining the approximation for a stress increase in an unbonded tendon at the ultimate limit state can be found in the literature and research reports. The following simple method assumes that in the maximum stressed point of a beam, e.g. in the middle of the single-span beam, a plastic joint occurs [22, 23]. The maximum deflection of the decisive span is estimated to be $f \approx l / 50$, which is usual for slabs [23]. The method also assumes that the single-span beam consists of two rigid halves after the formation of a concentrated crack in the centre of the span. The halves rotated around a joint in the compression zone. In the continuous structure, plastic hinges occur both in the spans and above the supports. The deformation figure for a two-span slab in the failure state has been compiled after references 21 and 22 and utilizing to the single-span theory mentioned above. This is illustrated in the Figure 8 . From the geometry of these parts follows:

$$
\tan \varphi=\varphi=\frac{f}{0,5 \cdot l} \text { or } \tan \varphi=\varphi=\frac{0,5 \cdot w}{d_{\mathrm{p}}-x}
$$

where $f$ is the deformation, $x$ is the height of the compression zone, $d_{\mathrm{p}}$ is the effective height of the tendon and $l$ is the length of the span. Combining these expression gives:

$$
w=\Delta l_{\mathrm{p}}=\frac{4 f \cdot\left(d_{\mathrm{p}}-x\right)}{l}
$$

By using the estimation $f \approx l / 50$ and a coefficient $k_{\mathrm{G}}$, which takes the joints into account, the following expression is obtained $[22,23]$ :

$$
\Delta l_{\mathrm{p}}=0,02 \cdot k_{\mathrm{G}}\left(d_{\mathrm{p}}-x\right)
$$

where $k_{\mathrm{G}}=4$ for a single span, $k_{\mathrm{G}}=6$ for the edge span of a continuous slab and $k_{\mathrm{G}}=8$ for the middle span of a continuous slab.

For a symmetrical two-span slab, assuming the same limit deflections and compression zone heights, the result is threefold. 


$$
\Delta l_{\mathrm{p}}=w_{1}+w_{2}+w_{3} \quad \text { when } \quad w_{\mathrm{i}}=0,08 \cdot\left(d_{\mathrm{p}}-x\right)
$$

The stress increase of the unbonded tendon can then be calculated from the equation:

$$
\Delta \sigma_{\mathrm{p}, \mathrm{ULS}}=\frac{\Delta l_{\mathrm{p}} \cdot E_{\mathrm{p}}}{l_{\mathrm{p}}}
$$

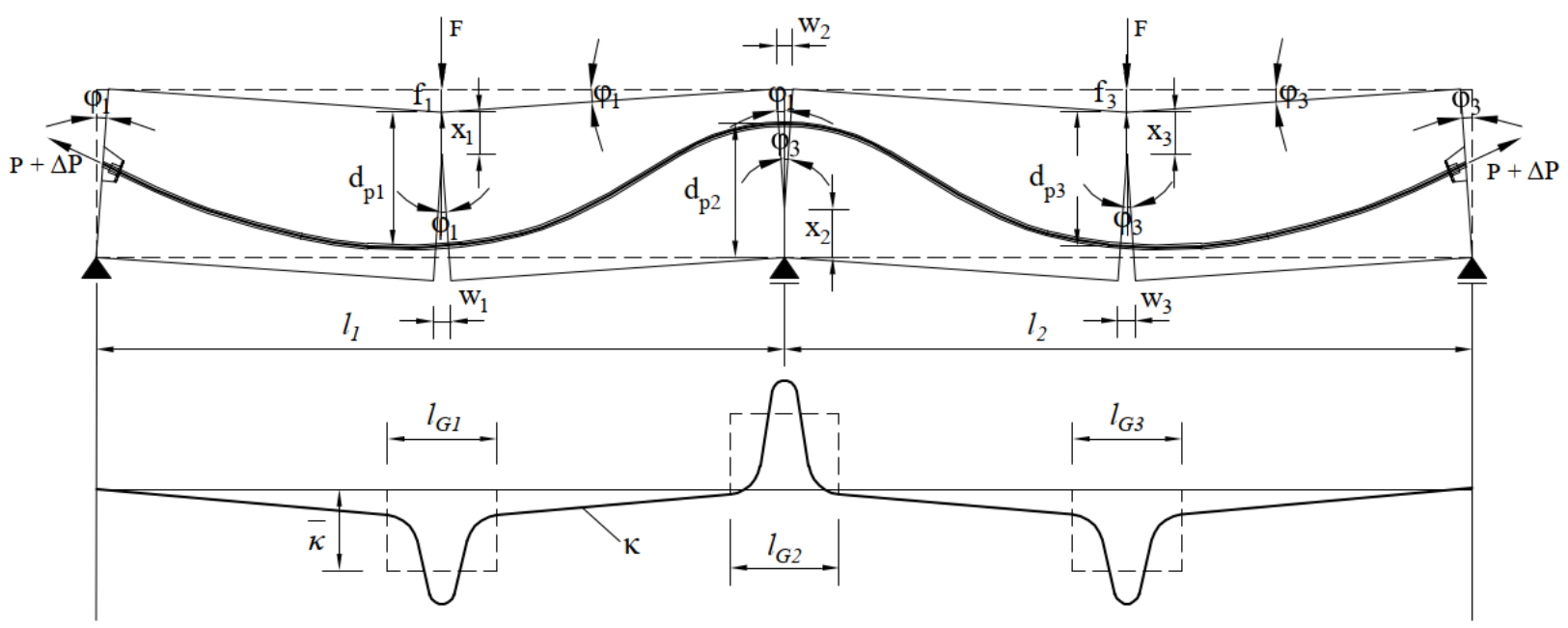

Figure 8-Deformation figure for a two-span slab in the failure state, figure compiled after [21,22].

Another approximation method presented by Kordina and Hegger [12] also takes into account the deformations of the structure. The tendon elongation is determined from the sum of concrete deformation in the fibre of the tendon, which is expediently determined, using the $M-\kappa$ relationship.

$$
\Delta \varepsilon_{\mathrm{p}, \mathrm{u}}=\frac{1}{l_{\mathrm{p}}} \int \varepsilon_{\mathrm{cp}, \mathrm{u}} d s=\frac{1}{l_{\mathrm{p}}} \int \kappa(x) \cdot(1-\xi) d_{\mathrm{p}} d s
$$

In Eq. (8) $\Delta \varepsilon_{\mathrm{p}, \mathrm{u}}$ means the increase in elongation of the prestressing steel in the ultimate limit state and $\Delta \varepsilon_{\mathrm{cp}, \mathrm{u}}$ is the expansion of the concrete at the height of the tendon. $\kappa$ is the curvature of the cross-section and $\xi$ is the relative height of the compression zone $\xi=x / h$. If the curvatures in the ultimate limit state are assumed to be essentially limited to the area $l_{\mathrm{G}}$, called the length of the plastic hinge, and the rest of the area remains in an uncracked state, the increase in elongation of the tendon can be calculated with the equation:

$$
\Delta \varepsilon_{\mathrm{p}, \mathrm{u}}=\frac{1}{l_{\mathrm{p}}} \bar{\kappa}(1-\xi) d_{\mathrm{p}} l_{\mathrm{G}}=\frac{1}{l_{\mathrm{p}}} k_{\mathrm{c}} k_{\mathrm{p}} k_{\mathrm{f}} l_{\mathrm{G}}
$$

In Eq. (9) the factors are as follows: $k_{\mathrm{c}}$ is the coefficient for the concrete strength, $k_{\mathrm{p}}$ is the coefficient for the prestressing steel, $k_{\mathrm{f}}$ is the coefficient for the component geometry, $l_{\mathrm{G}}$ is the length of the plastic hinge and $l_{\mathrm{p}}$ the tendon length.

Approximate values for the unknown parameters were determined by the experiment. 


$$
\begin{aligned}
& k_{\mathrm{c}} k_{\mathrm{p}}=\left(2,0+\frac{0,03 \cdot f_{\mathrm{ck}}}{\rho_{\mathrm{p}}}\right) \cdot 10^{-3} \leq 9,0 \cdot 10^{-3} \\
& k_{\mathrm{f}}=0,90+0,10 \frac{b_{\mathrm{f}}}{b_{\mathrm{w}}} \leq 1,20
\end{aligned}
$$

where $\rho_{\mathrm{p}}=100 \cdot A_{\mathrm{p}} / A_{\mathrm{c}}$ and $f_{\mathrm{ck}}$ is the strength of the concrete. The length of the plastic hinge is defined as follows.

$$
l_{\mathrm{G}}=\left(0,20+0,25 \frac{l_{\mathrm{b}}}{l_{0}}\right) \cdot l_{0}
$$

In Eq. (12), $l_{0}$ is the distance between the moment zero points and $l_{\mathrm{B}}$ the effective range of the load according to Figure 9.
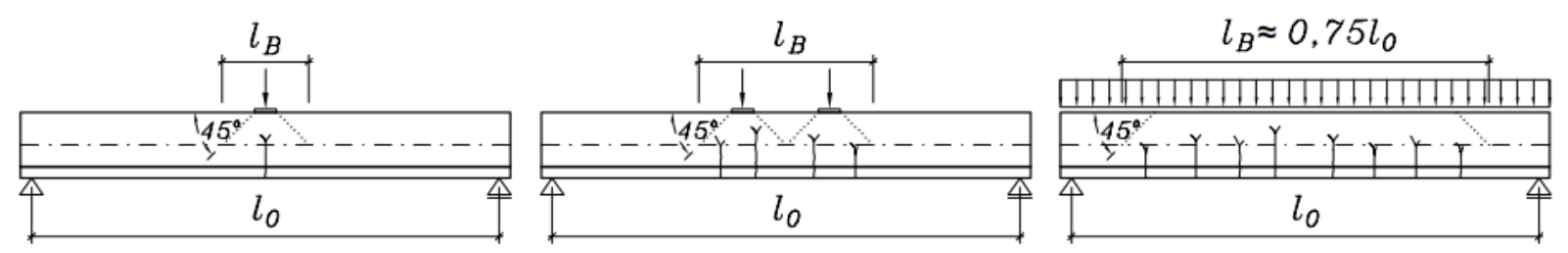

Figure 9 - The length $l_{\mathrm{B}}$ from Kordina and Hegger [12].

The $5 \%$ quantile value of the stress increase in an unbonded tendon in continuous members can be determined from Eq. $(13)[12,23]$ where $n$ stands for the number of joints.

$$
\Delta \sigma_{\mathrm{p}, \mathrm{ULS}}=0,65 \Delta \sigma_{\mathrm{p}, \mathrm{u}}=0,65 \frac{E_{\mathrm{p}}}{l_{\mathrm{p}}} \sum_{i=1}^{n} k_{\mathrm{c}, \mathrm{i}} \cdot k_{\mathrm{p}, \mathrm{i}} \cdot k_{\mathrm{f}, \mathrm{i}} \cdot l_{\mathrm{G}, \mathrm{i}}
$$

The model which takes into account several parameters that are known to influence the stress increase of unbonded tendon at ultimate capacity was presented by Harajli [7, 8, 9]. The equation is based on the plastic analysis and the concept of a collapse mechanism. The first part of the expression takes into account continuity, slenderness and load pattern of a structure as well as a relative amount of prestressing steel. The latter factor includes an effect of a neutral axis depth.

$$
\Delta \sigma_{\mathrm{p}, \mathrm{ULS}}=\left[\frac{\varphi_{\mathrm{ps}}}{\frac{L_{\mathrm{a}} / d_{\mathrm{p}}}{N_{\mathrm{p}} E_{\mathrm{p}} \varepsilon_{\mathrm{cu}}}+\frac{\rho_{\mathrm{p}}}{0,85 \beta_{1} f_{\mathrm{cd}}}}\right] \cdot\left[1-\frac{A_{\mathrm{p}} f_{\mathrm{pe}}+A_{\mathrm{s}} f_{\mathrm{y}}}{0,85 \beta_{1} f_{\mathrm{cd}} b d_{\mathrm{p}}}\right] \leq 0,95 f_{\mathrm{pk}}
$$

In the equation $\varphi_{\mathrm{ps}}$ is a stress reduction factor and the value of the factor used in the analysis was $0.75 . N_{\mathrm{p}}$ is a parameter that combines the effect of member continuity and type of applied load. It can be calculated from the Eq. (15):

$$
N_{p}=\left(\frac{20,7}{f}+10,5\right) n_{\mathrm{p}}^{+}+10,5 n_{\mathrm{p}}^{-}
$$

In Eq. (15), $n_{\mathrm{p}}{ }^{+}$and $n_{\mathrm{p}}{ }^{-}$are the minimum numbers of positive and negative plastic hinges. The factor $f=\infty$ for a single concentrated load and $f=6$ for uniform load. 
According to the Eurocode EN 1992-1-1 [20] it is generally necessary to take the deformations of the whole member into account when calculating the stress increase of the prestressing steel in the unbonded tendon. If a detailed analysis is not made, it can be assumed that the increase of the stress from the effective prestress to the stress in the ultimate limit state is limited to the value of $\Delta \sigma_{\mathrm{p}, \mathrm{ULS}}=100 \mathrm{MPa}$. More conservative values may be found in the National Annex.

The equation for calculating the stress increase in an unbonded tendon at ultimate capacity is presented in the current ACI 318-11 code considering the span-to-depth ratio of the member $\left(L / d_{\mathrm{p}}\right)$ as follows [24]:

$$
\begin{array}{ll}
\Delta \sigma_{\mathrm{p}, \mathrm{ULS}}=70+\frac{f_{\mathrm{cd}}}{100 \rho_{\mathrm{p}}}(M P a) & \text { when } L / d_{\mathrm{p}} \leq 35 \\
\Delta \sigma_{\mathrm{p}, \mathrm{ULS}}=70+\frac{f_{\mathrm{cd}}}{300 \rho_{\mathrm{p}}}(M P a) & \text { when } L / d_{\mathrm{p}}>35
\end{array}
$$

\section{Comparison of different models with the test results}

Zhou and Zheng, Maguire et al. and Weller have completed experimental tests of continuous twospan beams $[11,13,14,15]$. The measured values of the stress increase in unbonded tendons at ultimate capacity $\Delta \sigma_{\mathrm{p}, \mathrm{ULS}}$ from these tests have been compared with the results from the nonlinear finite element analysis. Comparative analyses have also been performed by using the simplified design equations from Harajli, as well as Kordina and Hegger and design equations from standards such as Eurocode EN 1992-1-1 and ACI 318-11. The results are shown in Figure 10. These have been presented as a function of the relative height of the compression zone $x / d_{\mathrm{e}}$, where $d_{\mathrm{e}}$ is the combined effective height of the reinforcement and tendons. The design standards Eurocode EN 1992-1-1 and ACI 318-11, as well as the equation by Kordina and Hegger, mostly gave values which are on the conservative side, compared to the test results. These are useful equations for design purposes. The results from the nonlinear analysis were close to the results from Harajli's method. Both models gave somewhat non-conservative values for the stress increase of the tendon. In the last part of the four diagrams, all the test results $[11,13,14,15]$ are compared to the values from the nonlinear analysis. About half of all points are on the unsatisfactory side and another half on the satisfactory side of the regression line from the design point of view. Probable reasons for the large scatter are the neglection of variation of the neutral axis and the lack of more detailed analyses of plastic rotations at the support area.

The ultimate moment capacity at the support area obtained from the test beams was presented in the research report by Zhou and Zheng [13]. Comparative analyses have been made by using the design equations from standards and Harajli, Kordina and Hegger, as well as the nonlinear analysis. The results are shown in Figure 11. 
Nordic Concrete Research - Publ. No. NCR 64 - ISSUE 1 / 2021 - Article 7, pp. 109-128

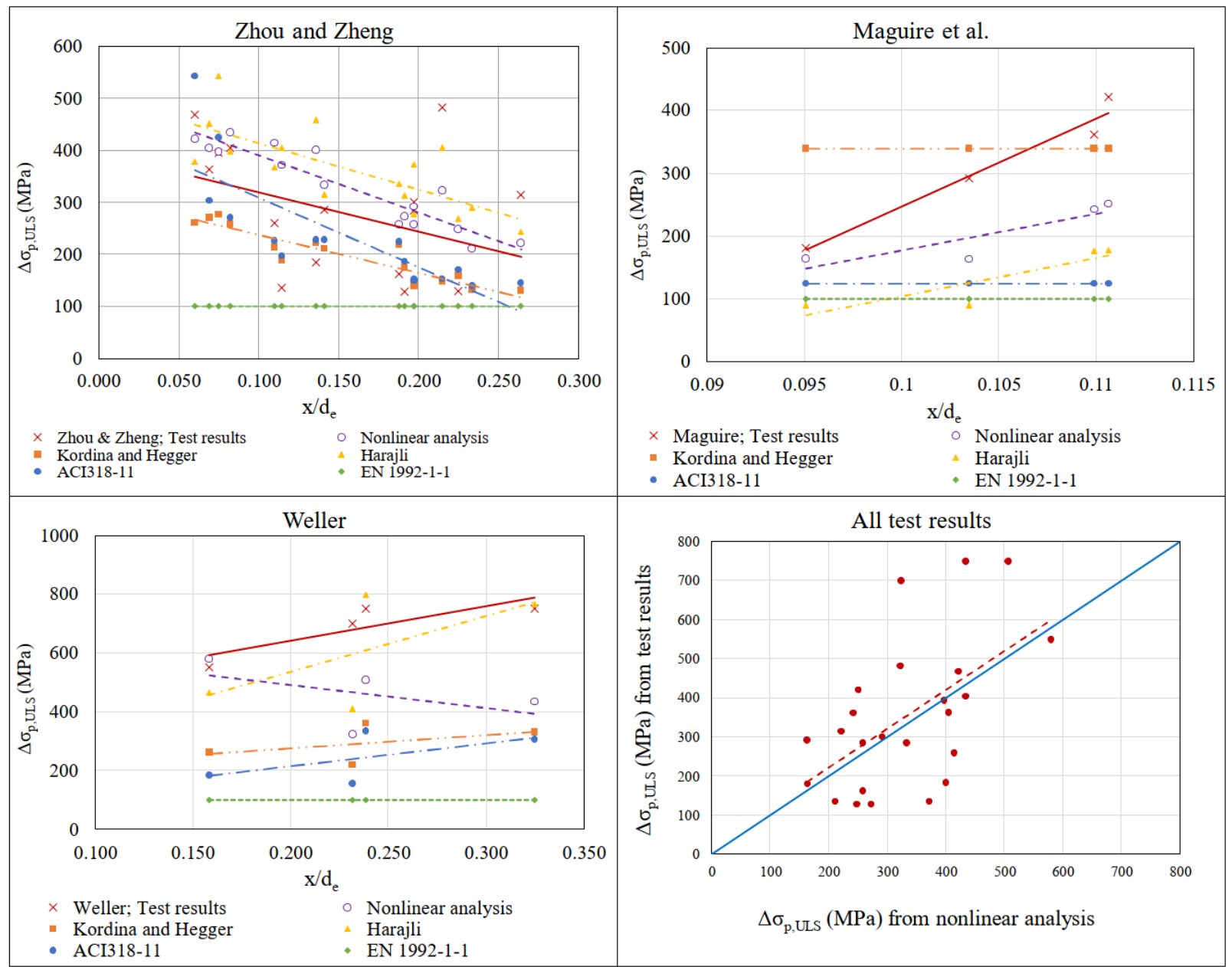

Figure 10 - Comparison of the stress increase of the tendon between the test results and the calculated values.

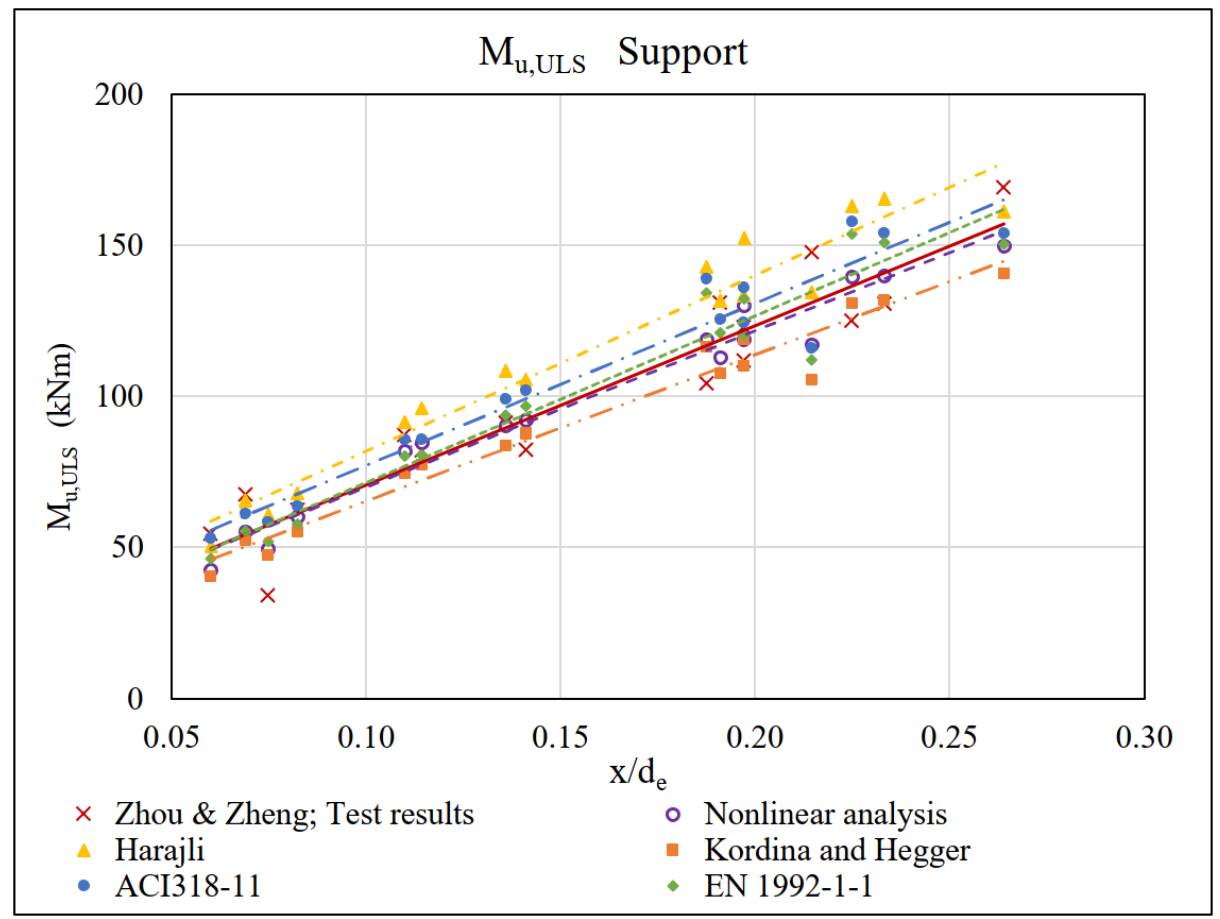

Figure 11 - The ultimate moment capacity at the support area. 
Figure 11 shows that all of the models have a rather good correlation with the test results. The stress increase of the unbonded tendon at the ultimate limit state is small compared to the effective prestress. For this reason, the effect of the stress increase in the unbonded tendon on the ultimate moment capacity of the support area is not that significant.

\section{6.}

\section{PARAMETRIC STUDY}

In the parametric study, the effect of different amounts of non-prestressed reinforcement on the stress increment of the unbonded tendon at the ultimate limit state was examined. The model and data of the examined two-span concrete beams are presented in Chapter 4. The study included the analysis of 92 different imaginary post-tensioned concrete beams (B1-B92). The reinforcement arrangements of the beams are collected in Table 1 located in appendix A. The amount of reinforcing steel bars in both tension $\left(A_{\mathrm{s}}\right)$ and compression $\left(A_{\mathrm{s}}{ }^{\prime}\right)$ fibres and the magnitude of the tendon force have been the variables in the analysis. The relationship between the amount of reinforcement in the support area and the reinforcement in the span has also been studied so that in some of the examined beams there was the same amount of reinforcement in the support area as there was in the span, and, in some other beams, the support reinforcement was double compared to the reinforcement in the span. Different reinforcement arrangements have been taken into account in the derivations of the moment-curvature relationships of the cross-sections of the examined beams. The results have been compared with the value calculated with the stress increase of $100 \mathrm{MPa}$ according to the Eurocode EN 1992-1-1 [20]. Comparative analysis has also been performed by using the methods by Hegger and Kordina, as well as Harajli presented in Chapter 5.

In Figure 12 the ultimate moment capacity at the support area calculated by the nonlinear analysis is compared to the ultimate moment capacity calculated by the other models. The results are presented as a function of the reinforcement ratio $\omega$ of the combined tension reinforcement, rebars and tendons. It can be seen from the figure that the results from the nonlinear analysis correspond well to the other models, at least up to the reinforcement ratio of 0.35 .

The stress increment of the tendon at the ultimate limit state from a nonlinear analysis compared with values from other models is shown in Figure 13. The symbols presented in the one chart of the Figure 13 refers to all the four diagrams in the same figure. The value of the stress increase is constant according to the Eurocode EN 1992-1-1 [20] as well as the model presented by Kordina and Hegger [12]. The nonlinear analysis gives slightly lower values for the stress increase of the tendon than the design equation by Harajli with low reinforcement ratios. With higher reinforcement ratios, the nonlinear analysis gives higher values than Harajli's equation. According to the nonlinear analysis the stress increase of the unbonded tendon is larger when the compression reinforcement is used, especially at high reinforcement ratios. The nonlinear analysis takes into account different amounts of tension and compression reinforcement and their effects on the deformation of the beam. Harajli's equation, used in the analysis, was the kind of alternative that doesn't take the compression reinforcement into account in the derivation of the stress increase. 


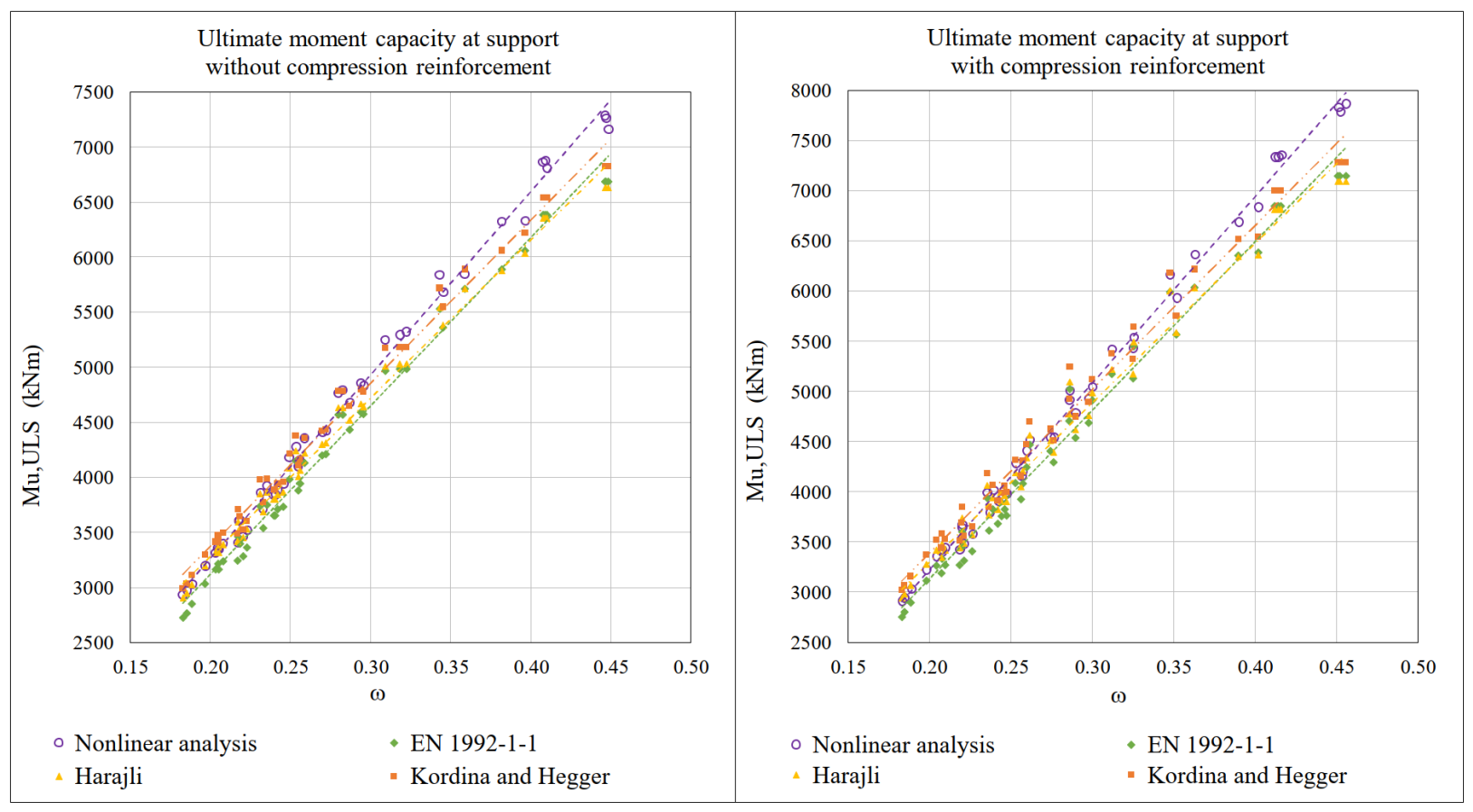

Figure 12 - Ultimate moment capacity at support area.

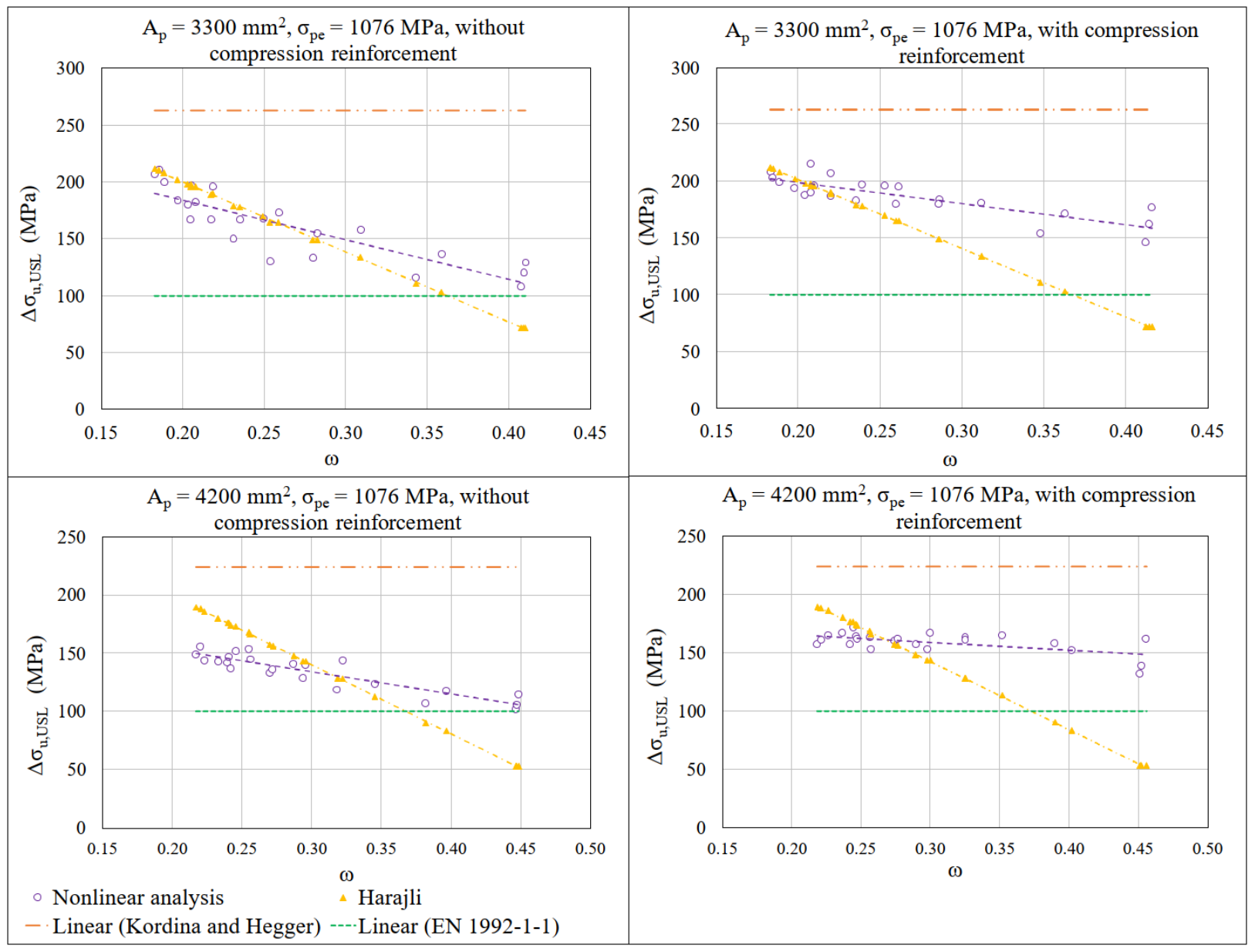

Figure 13 - The stress increment of the tendon at ultimate limit state. 
7.

\section{CONCLUSIONS}

A simplified nonlinear model has been used to determine the stress increase in the unbonded tendons at the ultimate and flexural moment capacity of the support area of the studied two-span concrete beams post-tensioned with unbonded tendons. The results have been compared to the test results of Zhou and Zheng, Maguire et al. and Weller [11, 13, 14, 15]. The comparative analyses have also been performed by using design equations from Eurocode standard EN 19921-1 and ACI 318-11, as well as two models from the literature, the Harajli equation and the design method by Kordina and Hegger. The effect of different amounts of non-prestressed reinforcement on the stress increment of the unbonded tendon at the ultimate limit state was examined in the parametric study. The following conclusions may be derived from both analyses:

- There is some variance in the values of the stress increase of the unbonded tendon between the test results and results obtained from the different models. The values of the stress increase calculated according to the Harajli equation corresponded best to the results from the presented nonlinear analysis.

- The maximum moment capacity in the support area of the two-span beams obtained by the nonlinear analysis corresponded well to the test results obtained from the test beams.

- In the parametric study, when determining the ultimate moment capacity at the support area, the results from the simplified nonlinear analysis correspond well to the results from the other models up to the reinforcement ratio of 0.35 .

- According to the nonlinear analysis in the parametric study, the stress increase of the unbonded tendon is larger when the compression reinforcement is used, especially at high reinforcement ratios.

- The code methods in ACI 318-11 and EN 1992-1-1 mostly gave conservative values for the stress increase of the unbonded tendon at the ultimate limit state in studied cases.

There is a need to continue the work and update the model so that the actual position of the neutral axis of the beam will be taken into account and parameters that account for plastic rotation at the support area will be included.

\section{REFERENCES}

1. Maguire M, Chang M, Collins W \& Sun Y: "Stress Increase of Unbonded Tendons in Continuous Post-Tensioned Members". Journal of Bridge Engineering ASCE, 22(2), 2017, $12 \mathrm{pp}$.

2. Mattock A H, Yamazaki J \& Kattula B T: "Comparative Study of Prestressed Concrete Beams, With and Without Bond". ACI Journal, V.68, No. 2, February 1971, pp. 116-125

3. Cooke N, Park R \& Yong P: "Flexural Strength of Prestressed Concrete Members with Unbonded Tendons". PCI Journal, 26(6), 1981, pp. 52-80

4. Du G \& Tao X: "Ultimate Stress of Unbonded Tendons in Partially Prestressed Concrete Beams". PCI Journal, V. 31, No 6, 1985, pp. 72-91

5. Burns N H, Charney F A \& Vines W R: "Tests of One-Way Post-Tensioned Slabs with Unbonded Tendons". PCI Journal, V. 33, No. 5, September-October 1978, 66-83

6. Harajli M H, Hijazi S: "Evaluation of the Ultimate Steel Stress in Partially Prestressed Concrete Members". PCI Journal, V.36, No. 1, 1991, pp 62-82.

7. Harajli M H: "On the Stress in Unbonded Tendons at Ultimate: Critical Assessment and Proposed Changes”. ACI Structural Journal, V. 103, No. 6, 2006, pp. 803-812 
8. Harajli M H: "Proposed Modification of AASHTO-LRFD for Computing Stress in Unbonded Tendons at Ultimate". Journal of Bridge Engineering ASCE, V.16, No. 6, 2011, pp. $828-838$

9. Harajli M H: "Tendon Stress at Ultimate in Continuous Unbonded Post-Tensioned Members: Proposed Modification of ACI 318, Eq. (18-4) and (18-5)". ACI Structural Journal, V. 109, No. 2, 2012, pp.183-192

10. Naaman A E \& Alkhairi F M: "Stress at Ultimate in Unbonded Post-Tensioned Tendons: Part 2 - Proposed Methodology". ACI Structural Journal, V.88, No. 6, NovemberDecember 1991, pp. 683-692

11. Weller B: "Experimentelle Untersuchungen zum Biegetragverhalten von Durchlaufträgen mit Vorspannung ohne Verbund“. Deutscher Ausschuss für Stahlbeton, Heft 391, Berlin 1988, Seite 73-125

12. Kordina K \& Hegger J: “Zur Ermittlung der Biegebruch-Tragfähigkeit bei Vorspannung ohne Verbund". Beton- und Stahlbetonbau, Heft 4, April 1987, Seite 85-90

13. Zhou W \& Zheng W Z: "Experimental Research on Plastic Design Method and Moment Redistribution in Continuous Beams Prestressed with Unbonded Tendons". Magazine of Concrete Research, V. 62, No. 1, 2010, pp. 51-64

14. Zhou W \& Zheng W Z: "Unbonded Tendon Stresses in Continuous Post-Tensioned Beams”. ACI Structural Journal, V.111, No. 3, May-June 2014, pp. 525-536

15. Maguire M, Collins W N, Halbe K R \& Roberts-Wollmann C L: "Multi-Span Members with Unbonded Tendons: Ultimate Strength Behavior". ACI Structural Journal, No. 113S18, March-April, 2016, pp. 195-204

16. Allouche E N, Campbell T I, Green M F \& Soudki K A: "Tendon Stress in Continuous Unbonded Prestressed Concrete Members - Part 2: Parametric Study”. PCI Journal, 44(1), 1999, pp. 60-72

17. Kim S K \& Lee D H: "Nonlinear Analysis Method for Continuous Post-Tensioned Concrete Members with Unbonded Tendons". Engineering Structures, 40, 2012, pp.487-500

18. $\mathrm{Vu} \mathrm{N} \mathrm{A,} \mathrm{Castel} \mathrm{A} \mathrm{\&} \mathrm{François} \mathrm{R:} \mathrm{"Response} \mathrm{of} \mathrm{Post-tensioned} \mathrm{Concrete} \mathrm{Beams} \mathrm{with}$ Unbonded Tendons including Serviceability and Ultimate State". Engineering Structures, 32(2), 2010, pp. 556-559

19. Zimmermann J: "Biegetragverhalten und Bemessung von Trägern mit Vorspannung ohne Verbund". Deutscher Ausschuss für Stahlbeton, Heft 391, Berlin 1988, Seite 5-71

20. European standard EN 1992-1-1, Eurocode 2: Design of concrete structures - Part 1-1: General rules and rules for buildings, 2005, $226 \mathrm{pp}$.

21. fib Model Code 2010 (2013), fib Model Code for Concrete Structures. International Federation for Structural Concrete. Berlin: Ernst \& Sohn, 2013, 402 p.

22. Rombach G: "Spannbetonbau". 2. Auflage, 2009, Seite 608

23. Krüger $\mathrm{W} \&$ Mertzsch O: "Spannbetonbau-Praxis nach Eurocode 2 Mit Berechnungsbeispielen”. 3. Auflage, Bauwerk BBB, Beuth, 2012, Seite 318

24. ACI Committee 318: "Building Code Requirements for Structural Concrete (ACI 318-11) and Commentary". American Concrete Institute, Farmington Hills, MI, 2011, 503 pp.

25. LUSAS Academic Bridge Plus software 


\section{APPENDIX A}

Table 1 - The input data of the nonlinear analysis

\begin{tabular}{|c|c|c|c|c|c|c|c|c|c|c|c|}
\hline & \multicolumn{5}{|c|}{$A_{p}=3300 \mathrm{~mm}^{2}, \sigma_{p e}=1076 \mathrm{MPa}$} & \multicolumn{6}{|c|}{$A_{p}=4200 \mathrm{~mm}^{2}, \sigma_{p e}=1076 \mathrm{MPa}$} \\
\hline Name & $\begin{array}{c}\text { Span A } \\
\mathrm{A}_{\mathrm{s}}\left(\mathrm{mm}^{2}\right)\end{array}$ & $\begin{array}{c}\text { Span B } \\
A_{s}\left(m^{2}\right)\end{array}$ & $\begin{array}{l}\text { Support } \\
A_{s}\left(\mathrm{~mm}^{2}\right)\end{array}$ & $\begin{array}{c}A_{s^{\prime}} \\
\left(\mathrm{mm}^{2}\right)\end{array}$ & $\begin{array}{c}A_{s^{\prime}} \\
\text { (Support) } \\
\left(\mathrm{mm}^{2}\right)\end{array}$ & Name & $\begin{array}{c}\text { Span A } \\
A_{s}\left(m^{2}\right)\end{array}$ & $\begin{array}{c}\text { Span B } \\
A_{s}\left(\mathrm{~mm}^{2}\right)\end{array}$ & $\begin{array}{l}\text { Support } \\
A_{s}\left(m^{2}\right)\end{array}$ & $\begin{array}{c}A_{s^{\prime}} \\
\left(\mathrm{mm}^{2}\right)\end{array}$ & $\begin{array}{c}A_{s^{\prime}} \\
\text { (Support) } \\
\left(\mathrm{mm}^{2}\right)\end{array}$ \\
\hline B-1 & 1470 & 1470 & 1470 & 804 & 804 & B-47 & 1470 & 1470 & 1470 & 804 & 804 \\
\hline B-2 & 1608 & 1608 & 1608 & 804 & 804 & B-48 & 1608 & 1608 & 1608 & 804 & 804 \\
\hline B-3 & 1885 & 1885 & 1885 & 804 & 804 & B-49 & 1885 & 1885 & 1885 & 804 & 804 \\
\hline B-4 & 2513 & 2513 & 2513 & 804 & 804 & B-50 & 2513 & 2513 & 2513 & 804 & 804 \\
\hline B-5 & 2945 & 2945 & 2945 & 804 & 804 & B-51 & 2945 & 2945 & 2945 & 804 & 804 \\
\hline B-6 & 3141 & 3141 & 3141 & 804 & 804 & B-52 & 3141 & 3141 & 3141 & 804 & 804 \\
\hline B-7 & 3927 & 3927 & 3927 & 1256 & 1256 & B-53 & 3927 & 3927 & 3927 & 1256 & 1256 \\
\hline B-8 & 4908 & 4908 & 4908 & 1256 & 1256 & B-54 & 4908 & 4908 & 4908 & 1256 & 1256 \\
\hline B-9 & 6434 & 6434 & 6434 & 1256 & 1256 & B-55 & 6434 & 6434 & 6434 & 1256 & 1256 \\
\hline B-10 & 8042 & 8042 & 8042 & 1256 & 1256 & B-56 & 8042 & 8042 & 8042 & 1256 & 1256 \\
\hline B-11 & 12063 & 12063 & 12063 & 1256 & 1256 & B-57 & 12063 & 12063 & 12063 & 1256 & 1256 \\
\hline B-12 & 16085 & 16085 & 16085 & 1256 & 1256 & B-58 & 16085 & 16085 & 16085 & 1256 & 1256 \\
\hline B-13 & 1470 & 1470 & 1470 & 1470 & 1470 & B-59 & 1470 & 1470 & 1470 & 1470 & 1470 \\
\hline B-14 & 1608 & 1608 & 1608 & 1608 & 1608 & B-60 & 1608 & 1608 & 1608 & 1608 & 1608 \\
\hline B-15 & 1885 & 1885 & 1885 & 1885 & 1885 & B-61 & 1885 & 1885 & 1885 & 1885 & 1885 \\
\hline B-16 & 2513 & 2513 & 2513 & 2513 & 2513 & B-62 & 2513 & 2513 & 2513 & 2513 & 2513 \\
\hline B-17 & 2945 & 2945 & 2945 & 2945 & 2945 & B-63 & 2945 & 2945 & 2945 & 2945 & 2945 \\
\hline B-18 & 3141 & 3141 & 3141 & 3141 & 3141 & B-64 & 3141 & 3141 & 3141 & 3141 & 3141 \\
\hline B-19 & 3927 & 3927 & 3927 & 3927 & 3927 & B-65 & 3927 & 3927 & 3927 & 3927 & 3927 \\
\hline B-20 & 4908 & 4908 & 4908 & 4908 & 4908 & B-66 & 4908 & 4908 & 4908 & 4908 & 4908 \\
\hline B-21 & 6434 & 6434 & 6434 & 6434 & 6434 & B-67 & 6434 & 6434 & 6434 & 6434 & 6434 \\
\hline B-22 & 8042 & 8042 & 8042 & 8042 & 8042 & B-68 & 8042 & 8042 & 8042 & 8042 & 8042 \\
\hline B-23 & 12063 & 12063 & 12063 & 8042 & 8042 & B-69 & 12063 & 12063 & 12063 & 8042 & 8042 \\
\hline B-24 & 16085 & 16085 & 16085 & 8042 & 8042 & B-70 & 16085 & 16085 & 16085 & 8042 & 8042 \\
\hline B-25 & 1470 & 1470 & 2945 & 804 & 804 & B-71 & 1470 & 1470 & 2945 & 804 & 804 \\
\hline B-26 & 1608 & 1608 & 3217 & 804 & 804 & B-72 & 1608 & 1608 & 3217 & 804 & 804 \\
\hline B-27 & 1885 & 1885 & 3770 & 804 & 804 & B-73 & 1885 & 1885 & 3770 & 804 & 804 \\
\hline B-28 & 2513 & 2513 & 5026 & 804 & 804 & B-74 & 2513 & 2513 & 5026 & 804 & 804 \\
\hline B-29 & 2945 & 2945 & 5890 & 804 & 804 & B-75 & 2945 & 2945 & 5890 & 804 & 804 \\
\hline B-30 & 3141 & 3141 & 6434 & 804 & 804 & B-76 & 3141 & 3141 & 6434 & 804 & 804 \\
\hline B-31 & 3927 & 3927 & 8042 & 1256 & 1256 & B-77 & 3927 & 3927 & 8042 & 1256 & 1256 \\
\hline B-32 & 4908 & 4908 & 9650 & 1256 & 1256 & B-78 & 4908 & 4908 & 9650 & 1256 & 1256 \\
\hline B-33 & 6434 & 6434 & 12868 & 1256 & 1256 & B-79 & 6434 & 6434 & 12868 & 1256 & 1256 \\
\hline B-34 & 8042 & 8042 & 16085 & 1256 & 1256 & B-80 & 8042 & 8042 & 16085 & 1256 & 1256 \\
\hline B-35 & 10455 & 10455 & 16085 & 1256 & 1256 & B-81 & 10455 & 10455 & 16085 & 1256 & 1256 \\
\hline B-36 & 1470 & 1470 & 2945 & 1470 & 1470 & B-82 & 1470 & 1470 & 2945 & 1470 & 1470 \\
\hline B-37 & 1608 & 1608 & 3217 & 1608 & 1608 & B-83 & 1608 & 1608 & 3217 & 1608 & 1608 \\
\hline B-38 & 1885 & 1885 & 3770 & 1885 & 1885 & B-84 & 1885 & 1885 & 3770 & 1885 & 1885 \\
\hline B-39 & 2513 & 2513 & 5026 & 2513 & 2513 & B-85 & 2513 & 2513 & 5026 & 2513 & 2513 \\
\hline B-40 & 2945 & 2945 & 5890 & 2945 & 2945 & B-86 & 2945 & 2945 & 5890 & 2945 & 2945 \\
\hline B-41 & 3141 & 3141 & 6434 & 3141 & 3141 & B-87 & 3141 & 3141 & 6434 & 3141 & 3141 \\
\hline B-42 & 3927 & 3927 & 8042 & 3927 & 3927 & B-88 & 3927 & 3927 & 8042 & 3927 & 3927 \\
\hline B-43 & 4908 & 4908 & 9650 & 4908 & 4908 & B-89 & 4908 & 4908 & 9650 & 4908 & 4908 \\
\hline B-44 & 6434 & 6434 & 12868 & 6434 & 6434 & B-90 & 6434 & 6434 & 12868 & 6434 & 6434 \\
\hline B-45 & 8042 & 8042 & 16085 & 8042 & 8042 & B-91 & 8042 & 8042 & 16085 & 8042 & 8042 \\
\hline B-46 & 10455 & 10455 & 16085 & 8042 & 8042 & B-92 & 10455 & 10455 & 16085 & 8042 & 8042 \\
\hline
\end{tabular}

